\section{$\underset{\text { hommes }}{\text { \& migrations }}$}

\section{Hommes \& migrations}

Revue française de référence sur les dynamiques

migratoires

1305 | 2014

L'exil chilien en France

\title{
La culture vietnamienne en Aquitaine
}

L'exemple de l'Association franco-vietnamienne Bordeaux-Aquitaine

\section{André Le Vagueresse}

\section{OpenEdition}

1 Journals

\section{Édition électronique}

URL : http://journals.openedition.org/hommesmigrations/2764

DOI : 10.4000/hommesmigrations.2764

ISSN : 2262-3353

\section{Éditeur}

Musée national de l'histoire de l'immigration

\section{Édition imprimée}

Date de publication : 1 janvier 2014

Pagination : 168-170

ISBN : 978-2919-040261

ISSN : $1142-852 X$

\section{Référence électronique}

André Le Vagueresse, «La culture vietnamienne en Aquitaine », Hommes \& migrations [En ligne], 1305 |

2014, mis en ligne le 10 juillet 2014, consulté le 22 septembre 2020. URL : http://

journals.openedition.org/hommesmigrations/2764; DOI : https://doi.org/10.4000/

hommesmigrations. 2764 


\title{
LA CULTURE VIETNAMIENNE EN AQUITAINE L'EXEMPLE DE L'ASSOCIATION FRANCO-VIETNAMIENNE BORDEAUX-AQUITAINE
}

\author{
ANDRÉ LE VAGUERESSE, président de Liên-Viêt, cofondateur de l'Association \\ franco-vietnamienne Bordeaux-Aquitaine.
}

es pratiques culturelles des Vietnamiens en France restent souvent méconnues, voire inconnues de la population française, excepté la Fête du Têt, souvent assimilée au Nouvel An Chinois. Pourtant, localement, ici et là, la culture vietnamienne peut s'exprimer, comme en témoigne l'Association franco-vietnamienne Bordeaux-Aquitaine, dont l'histoire et les activités illustrent une migration multiple et ancienne dans la région.

C'est par hasard que celle-ci naît en 1992. Par hasard, quoique : dès les années 1920, la capitale de l'Aquitaine comptait une association d'étudiants vietnamiens qui fut, comme tous les cercles d'étudiants et de travailleurs de l'époque, un lieu de débats politiques où circulaient les idées révolutionnaires anticolonialistes. Donc, ce hasard qui n'en est pas un réunit et associe à l'aube des années 1990 une poignée de Vietnamiens et de Français autour d'un projet un rien anachronique : enseigner la langue et la civilisation vietnamiennes.

À qui ? À nous-mêmes d'abord! Le Vietnam est alors en train de s'ouvrir doucement, les guerres et les déchirures semblent - mais semblent seulement - s'éloigner. Des liens, des histoires se retissent entre ici et là-bas, l'impossible devient envisageable. Comme un terrain laissé en jachère à défricher.

\section{Balayer les clichés}

Ce sera donc l'association Cours de vietnamien de Bordeaux, un nom si peu séduisant que nous n'intéressons guère les institutions. L'enseignante est une Vietnamienne de la diaspora post-1975. L'équipe associative, à majorité féminine, est issue de vieilles familles vietnamiennes de Bordeaux, proche de l'Union générale des Vietnamiens de France (UGVF) ; on y trouve aussi quelques Français qui ont un lien avec le Vietnam ou qui sont simplement intéressés par la page d'histoire commune à la France et au Vietnam. Changer de paradigme, balayer les clichés: tel est le fil rouge, tacite mais fondamental, qui guide le projet. II s'agit de valoriser la culture et la civilisation vietnamiennes, sans s'arrêter sur les divisions entre ceux qui viennent du Sud ou du Nord. Seul le projet associatif compte. D’ailleurs, pour éviter toute confusion, ce sont les Français qui communiquent à l'extérieur.

Au fils des premières années, l'audience de l'association s'étend à tous les Vietnamiens, Eurasiens, Français d'Indochine, que les vagues migratoires ont amenés sur les côtes girondines, leurs enfants et leurs petits-enfants : travailleurs indochinois requis lors des deux guerres mondiales, citoyens 
français d'Indochine rapatriés en 1956, étudiants et universitaires des années 1960, boat-people des années 1975-1980, migrants économiques de toutes époques, bref tout ce que la minorité vietnamienne compte en France comme trajectoires diverses et multiples. Dans cet ensemble métissé et très divers, la question de la vietnamité (adhésion aux valeurs culturelles du Vietnam) est intimement liée au vécu personnel.

Peu à peu, au sein de l'association, ces trajectoires de vie se sont spontanément, par surprise, exprimées. Des histoires souvent douloureuses, marquées par une séparation, une rupture : “...la dernière fois que j'ai vu ma mère lors d'un voyage à Saigon en 1972...", "... quand les soldats français m'ont confiée à un orphelinat, j'ai appris que je ne devrais plus jamais parler vietnamien"... Nous avons alors pris conscience que nous avions créé bien autre chose qu'un simple cours de vietnamien du samedi matin.

\section{Quand la culture vietnamienne s'interroge sur elle-même}

Grâce à notre indépendance jalousement défendue, nous avons pu nouer des relations tant avec les communautés catholique et bouddhiste, qu'avec des représentants de l'ambassade du Vietnam, des écrivains contestés par le régime, toutes personnes que nous avions envie de rencontrer. Soutenus par le réseau des restaurateurs vietnamiens (réseau communautaire fréquent à l'étranger), nous avons grandi, accepté de nous faire connaître et de dépasser une discrétion quasi maladive. Nous avons présenté des candidats au Deug de vietnamien à Jussieu Paris 7, recon- naissance ultime. Nous organisons une fête pour le Têt où les Français invités sont accueillis comme des amis, des rencontres littéraires, des colloques. L'action culturelle s'est naturellement développée, tout comme les partenariats institutionnels avec le Musée d'Aquitaine, le Réseau Aquitaine pour l'histoire de la mémoire de l'immigration (Rahmi), l'agence culturelle de la Gironde (l'Iddac)... Le Cours de vietnamien de Bordeaux s'est ainsi mû en Association franco-vietnamienne Bordeaux-Aquitaine. Dans un cadre d'entraide et de solidarité, il est devenu un point d'information et de rencontre des nombreux réseaux associatifs vietnamiens et franco-vietnamiens de Bordeaux et de Gironde', qu'ils aient une vocation caritative, éducative, culturelle ou religieuse, mais tous tendent à garder un lien avec le pays. Des réseaux peu visibles, très fragmentés, voire cloisonnés, qui s'ignorent, se croisent, s'affrontent parfois, mais aussi se recomposent, s'allient.

Le parcours de l'Association franco-vietnamienne Bordeaux-Aquitaine illustre la vie de la communauté vietnamienne ces vingt-cinq dernières années en région bordelaise. Partie d'une association quelque peu communautariste, elle se métisse au fur et à mesure et s'ouvre sur l'extérieur. La culture vietnamienne ne s'exprime plus uniquement dans un cadre réservé mais se donne à voir et s'interroge sur elle-même : qu'est-ce qu'être vietnamien en France? Ou plutôt, qu'estce que la vietnamité ? Pourquoi je la revendique, pourquoi je la recherche?

Entre assimilation, insertion et intégration, mille réponses possibles, parce que autant de trajectoires autant d'histoires, encore souvent tues ou occultées, qui méritent d'être racontées, connues. 